Swarthmore College

Works

\title{
Crowding Out Morality: How The Ideology Of Self-Interest Can Be Self-Fulfilling
}

Barry Schwartz

Swarthmore College, bschwar1@swarthmore.edu

Follow this and additional works at: https://works.swarthmore.edu/fac-psychology

Part of the Psychology Commons

Let us know how access to these works benefits you

\section{Recommended Citation}

Barry Schwartz. (2012). "Crowding Out Morality: How The Ideology Of Self-Interest Can Be Self-Fulfilling". Psychology, Ideology, And Law. 160-184.

https://works.swarthmore.edu/fac-psychology/525

This work is brought to you for free by Swarthmore College Libraries' Works. It has been accepted for inclusion in Psychology Faculty Works by an authorized administrator of Works. For more information, please contact myworks@swarthmore.edu. 


\title{
Crowding Out Morality: How the Ideology of Self-Interest Can Be Self-Fulfilling
}

\author{
Barry Schwartz
}

So far as I am aware, we are the only society that thinks of itself as having arisen from savagery, identified with a ruthless nature. Everyone else believes they are descended from gods....Judging from social behavior, this contrast may be a fair statement of the differences between ourselves and the rest of the world. We make both a folklore and a science of our brutish origins, sometimes with precious little to distinguish between them.

- Marshall Sahlins, The Use and Abuse of Biology

Suppose you are directing a daycare center and encounter a problem. The center closes at 6 P.M., but a significant number of parents habitually pick up their kids 10 to 15 minutes late. It is justifiably annoying to your staff, which regards it as a sign of disrespect. You tack up reminders of the daycare center's hours. You send notices home. But the problem persists. Your warnings become more strident and moralistic, to no avail. You seem to be stuck. Parents know that you cannot close up and leave toddlers outside and alone.

In desperation, you impose a modest fine for lateness, less than the cost of a parking ticket. Will this solve the problem? Uri Gneezy and Aldo Rustichini (2000a; see also Gneezy \& Rustichini, 2000b) found out through an experiment at Israeli daycares. Initially, parents came late about $25 \%$ of the time. When the daycares introduced fines, the percentage of latecomers rose. As the fine imposition continued, lateness continued to increase, almost doubling by the $16^{\text {th }}$ week. The daycares then discontinued the fines. Lateness increased even more.

Why did the fines have that paradoxical effect? The title of Gneezy and Rustichini's article tells us: "A fine is a price." We know that a fine is not theoretically a price. A price is what you pay for a service or a good. It is an element of an exchange between willing participants. A fine, in contrast, is a punishment for a transgression. A $\$ 25$ parking ticket is not the price for parking; it is the 
penalty for parking illegally. However, the idea that a fine is a punishment is not chiseled in stone, and there is nothing to stop people from interpreting a fine as a price. If it costs $\$ 30$ to park in a downtown garage, you may calculate that it is cheaper to park illegally on the street. You are not doing the "wrong" thing; you are doing the economical thing. To get you to stop, we would need to make the fine (price) for parking illegally higher than the price for parking in a garage.

The same phenomenon seems to have occurred in the daycare centers. Prior to the imposition of fines, parents knew it was wrong to come late. Some parents still came late because other factors outweighed moral considerations. However, they certainly knew that coming late constituted a violation. When the daycares imposed fines, however, the moral dimension of the parents' behavior disappeared. It became a straightforward economic calculation, and lateness increased. "They're giving me permission to be late. Is it worth $\$ 25$ ? Is that a good price to pay to let me stay in the office a few minutes longer? Sure is!" Or perhaps the moral dimension of the behavior did not disappear, but parents judged that the fines constituted enough compensation that lateness was no longer immoral, which is just another way of saying that a fine became a price.

As the daycare center director, you might be tempted to stand on a table and yell at the top of your lungs: "No, no, no! A fine is not a price. A fine does not give you permission to be late! It merely underlines how serious of a transgression lateness is." But you would be wasting your breath. The fine gives parents permission to reframe their behavior as an exchange of a fee (the "fine") for a service (15 minutes of extra care). Moral considerations are just beside the point. And once lost, that moral dimension to lateness seems hard to recover. In Gneezy and Rustichini's study, high lateness rates prevailed even four weeks after the fines had been removed. It is as though the introduction of fines permanently altered parents' framing of the situation from a moral transaction to an economic one. When the fines were lifted, lateness simply became a better deal.

Prior to the imposition of fines, parents had one good reason for showing up on time: they felt morally obligated to do so, and coming late would violate a social contract. When the daycares introduced fines, a second reason was introduced: not only was lateness a moral violation, but it cost money. Ostensibly, two reasons are better than one, so lateness should have gone down. Instead, it went up. Though it seems perfectly reasonable to assume that motives add-that two reasons are better than one, three are better than two, and so on-this study shows that at least sometimes motives compete. Adding fines does not give parents a second reason to be on time but, rather, it cancels their first reason. In fact, the fines would have had to be draconian to match the moral sanctions that they were replacing. 
Gneezy and Rustichini point out a second interpretation of their findings-one that their data cannot rule out. The implicit contract between parents and the daycare center is "incomplete," in that no penalty for coming late is specified. Some parents might imagine the consequences of lateness to be quite serious ("Heavens, if I come late, they'll expel my child!") The fine specifies that aspect of the incomplete contract, and the penalty for lateness is less severe than at least some parents imagine. On that view, parents are always engaged in cost-benefit calculations, and they refrain from coming late because the costs they imagine far exceed the benefits of coming late. The imputation of that sort of cost-benefit calculation is impossible to refute. It is worth noting, however, that such a view presumes that "it's wrong" is never the reason people refrain from transgressing-that all decisions are based on some calculation of consequences.

Bruno Frey and Felix Oberholzer-Gee (1997) also discovered evidence of motivational competition when they assessed the views of Swiss citizens regarding the siting of nuclear waste dumps. At the time, Switzerland was preparing to have a national referendum about the location of future nuclear waste dumps. Citizens generally held strong views about the issue and were well informed. When asked whether they would be willing to have a waste dump in their community, $51 \%$ of respondents said yes-despite the fact that people generally thought such a dump was potentially dangerous and would lower their property values. Nearly $40 \%$ of respondents believed that the risk of a contaminating accident was significant, and nearly $80 \%$ of respondents believed that such an accident would result in long-term ill effects for many local residents. However, dumps had to go somewhere, and like it or not, people had obligations as citizens.

Frey and Oberholzer-Gee asked other people a slightly different question. The researchers asked whether people would be willing to have the dumps in their communities in return for an annual payment equivalent to six weeks' worth of an average Swiss salary. The respondents now had two reasons to say yes: obligations as citizens and financial incentives. Yet in response to that question, only $25 \%$ of respondents agreed. Adding the financial incentive cut acceptance in half!

Again, it seems self-evident that if people have one good reason to do something and you give them a second reason, they will be more likely to do it. Yet the respondents with two reasons to accept a nuclear waste site were less likely to say yes than those with one. Frey and Oberholzer-Gee explained that result by arguing that reasons sometimes compete, and that financial motives can "crowd out" moral ones. The respondents who were not offered cash incentives had to decide whether their responsibilities as citizens outweighed their distaste for having nuclear wastes dumped in their backyards. 
Some thought yes and others thought no. But that was the only question they had to answer.

The situation was more complex for the respondents who were offered cash incentives. They had to answer another question before deciding whether to accept the nuclear waste dump in their community: "Should I approach this dilemma as a Swiss citizen or as a self-interested individual? Citizens have responsibilities, but they're offering me money. Maybe the cash is an implicit instruction to answer the question based on the calculation of self-interest." Now, taking the lead of the questioners, citizens framed the waste-siting issue as an economic issue. With their self-interested hats squarely on their heads, most citizens concluded that six weeks' pay was not enough. In fact, the respondents who rejected the first offer were then offered $50 \%$ more money, and every respondent but one rejected the second offer as well. The offer of money undermined the moral force of the situation. ${ }^{1}$

In one more example, James Heyman and Dan Ariely (2004) showed that people would work harder for no money than for a modest payment. In one study, they asked college students to drag a digital ball repeatedly across a computer screen for 3 minutes. They told some students, but not others, that they would receive monetary compensation for completing the task. The students expecting compensation put in less effort, as measured by the number of balls they dragged across the screen. ${ }^{2}$ When no money was available, people acted on the basis of social motives: they were doing someone a favor. But when money was available, it became a market transaction. If they were going to work for pay, they needed to be paid enough.

Those three studies illustrate the central theme of this chapter. It is tempting to assume, as economists typically do, that motivation is exogenous to the situation at hand. If you want to influence people to do something, you have to discover what motivates them and then structure a situation so that those motives can be satisfied. Related to that deep assumption is the additional one that money-the "universal pander" - is a good proxy for the idiosyncratic motives that individuals possess, because money can be exchanged for almost anything else. In contrast, the three studies suggest that, rather than being exogenous to situations, motives can be created by situations. Israeli parents do not view their lateness as a market transaction until they are fined. Swiss citizens do not view their willingness to accept a waste dump as a market transaction until they are offered compensation. Offers of payment or threats of fines do not tap into a motivational structure so much as they establish a motivational structure.

This chapter will also make a second, related argument. So long as society endorses the legitimacy of different motives for different actions in different situations, Israeli parents or Swiss citizens might ask themselves what motives 
ought to govern their actions in the particular situation they face. They know that they have moral obligations. The question is, should those obligations govern their behavior in this particular situation? However, when one motive gets society's official seal of approval to dominate all others, people may stop appreciating that there are multiple types of motivations from which to choose. I will speculate that modern Western society's enthusiastic embrace of the view that self-interest simply is what motivates human behavior has led us to create social structures that cater to self-interest. As a result, we have shaped a society in which the assumption that self-interest is dominant is often true. We have not so much discovered the power of self-interest as we have created the power of self-interest. With a debt to Karl Marx, I call such processes "ideology."

\section{IDEA TECHNOLOGY AND IDEOLOGY}

We live in a culture and an age in which the influence of scientific technology is obvious and overwhelming. No one who uses a computer, a smartphone, or an MP3 player needs to be reminded of the power of technology. Nor do people having PET, CT, and MRI scans, fetuses monitored, genes spliced, or organs transplanted. None of that is news. Adjusting to ever-advancing technology is a brute fact of contemporary life. Some of us do it grudgingly, and some of us do it enthusiastically, but everyone does it.

When we think about the modern impact of science, most of us think about the technology of computers and medical diagnostics-what might be called "thing technology." However, science produces another type of technology that has a similarly large impact on us but is harder to notice. We might call it "idea technology." In addition to creating things, science creates conceptsways of understanding the world and our place in it-that have an enormous effect on how we think and act. If we understand birth defects as acts of God, we pray. If we understand them as acts of chance, we grit our teeth and roll the dice. If we understand them as the product of prenatal abuse and neglect, we take better care of pregnant women. Likewise, if we understand car accidents as acts of God, we pray. If we understand them as a function of poorly designed roads, we redesign our highways. If we understand them as the result of individuals not choosing to drive safely, we increase legal penalties for speeding and other traffic violations.

If we define "technology" broadly as the use of human intelligence to create objects or processes that change the conditions of daily life, then it seems clear that ideas are no less products of technology than are computers. However, two factors distinguish idea technology from thing technology. First, ideas are intangible and thus cannot be sensed directly. Therefore, they can suffuse 
through the culture and profoundly affect people before being noticed. Second, idea technology, unlike thing technology, can profoundly affect people even if the ideas are false. I will call the idea technology that is based on untrue ideas "ideology. ${ }^{13}$ Computers, microwaves, nuclear power plants, and other thing technologies generally do not affect people's lives unless they work. Companies cannot sell useless technological objects-at least not for long. In contrast, untrue ideas can affect how people act as long as people believe them. In some respects, we must monitor idea technology more vigilantly than thing technology because it often goes unnoticed, and it can have profound effects even when it is false, or when it is mere "ideology" (see Schwartz, 1997, for an elaboration).

\section{SKINNERIAN PSYCHOLOGY}

The potentially potent role of ideology can be illustrated with an example, a critical interpretation of the work of B. F. Skinner that I developed with two colleagues several years ago and that relates to the three examples that opened this chapter (Schwartz, Schuldenfrei, \& Lacey, 1978; see also Schwartz, 1986, $1988,1990)$. Skinner's central claim was that virtually all animal and human behavior is controlled by its rewarding or punishing consequences. Skinner illustrated that claim with research on pigeons and rats: if a rat receives food pellets consistently after pressing a lever, it will press the lever more often; if the rat receives a painful electric shock after lever pressing, it stops. For Skinner, the behavior of the lever-pressing rat tells the explanatory story of virtually all the behavior of all organisms. To understand behavior, it is necessary and sufficient to identify rewarding and punishing consequences.

Most of Skinner's critics over the years challenged him for being too reductive and for denying the importance, or even the existence, of concepts such as mind, freedom, and autonomy. Those critics contended that Skinner's account was not so much false as incomplete and inadequate with regard to human behavior; if one looked with any care at human behavior, one would find numerous phenomena that did not fit the Skinnerian worldview. Skinner and his followers usually responded to such criticisms by offering Skinnerian interpretations of the putatively disconfirming phenomena.

Our own approach was different. We suggested that just a casual glance at the nature of life in modern industrial society provided ample justification for the Skinnerian worldview - that is, we agreed with Skinner that virtually all behavior in modern industrial society is controlled by rewards. If one looks at the behavior of industrial workers in a modern workplace, it would be difficult to deny that rats pressing levers for food has a great deal in common with 
human beings pressing slacks in a clothing factory. Unlike Skinner, however, we argued that this does not reflect basic, universal facts about human nature but, rather, reflects the conditions of human labor ushered in by industrial capitalism. We suggested that with the development of industrial capitalism, work organization was restructured so that it came to look just like rat leverpressing. The last stages of that restructuring, influenced by the "scientific management" movement of F.W. Taylor (1911/1967), deliberately eliminated all influences on the rate and quality of human labor other than the wagethe reward. Each worker's tasks became so tedious and trivial that he simply had no other reasons to work hard. The manager could thus exercise complete control over workers by simply manipulating wage rates and schedules. Skinner developed his own theory in a world in which people spent much of their time behaving just as he said they would.

What followed from our argument was that human behavior could look more or less like the behavior of rats pressing levers depending on how the human workplace and other social institutions like schools, mental hospitals, and prisons were structured. And the more that the institutions were structured in keeping with Skinner's theory, the truer that theory would look-no, the truer that theory would be. Thus, Skinner's theory was ideology-a false piece of idea technology that came to seem more and more true as social institutions were shaped in its image.

The three examples with which this chapter began can be seen as illustrations of just that process of ideology in action. If you fine or reward people, it will look like their behavior is completely governed by fines and rewards. ${ }^{4}$ Matters of responsibility-of what is right-will disappear. In a world that is dominated by incentive manipulations, an open-minded social scientist might conclude, as Skinner did, that the only way to get people to do something is to make it worth their while. In addition, a legal scholar or judge might conclude that the only way to deter people from committing crimes is to punish criminals harshly enough so that crimes are no longer worth it. That would be correct as a matter of history, but incorrect as a matter of revealed human essences. The examples above are buttressed by a large literature on what is now called the "overjustification effect," which demonstrates how the introduction of rewards for tasks that are normally undertaken without them can change both people's motives to engage in the tasks and the manner in which the tasks are performed (see Lepper, Greene, \& Nisbett, 1973; Lepper \& Greene, 1978; Schwartz, 1982, 1988, 1990).

To summarize, we argued that Skinner's view of human behavior was substantially plausible in the social and economic context in which it arose, though it would not have been plausible in all other contexts. Moreover, and 
more important, as the theory was embraced and applied by introducing Skinnerian techniques broadly throughout society, it would come to look more and more plausible. Thus, someone growing up in a post-Skinnerian world in which rewards were routinely manipulated by parents, teachers, clergy, physicians, and law-enforcement agents would surely believe that the control of human behavior by such rewards was universal and inevitable. Such a person would be right about the universality but not about the inevitability.

It is important to understand that we were not arguing that Skinner's worldview was an invention. It captured a significant social phenomenon that he saw all around him. We argued instead that the social phenomenon was itself an invention, and that once it was in place, it made Skinner's worldview seem plausible. Further, we were not arguing that simply believing Skinner's worldview was sufficient to make it true. Rather, we argued that believing Skinner's worldview would lead to practices that shaped social institutions in a way that made it true. That dynamic is what makes Skinner's worldview an example of ideology. It is false as a general account of human nature. But then it is embraced and used to reshape one social institution after another. When such reshaping occurs, dramatic changes in behavior follow. As a result, an initially false idea- $a$ bit of ideology - becomes increasingly true.

There are at least three different routes by which ideology can become selffulfilling (Schwartz, 1997). The first is by changing how people think about or construe their own actions (for example, "I thought I was acting altruistically. Now social scientists are telling me that I work in a homeless shelter for ego gratification."). If that reconstrual mechanism is acting, nothing outside the person necessarily changes. The person simply understands her actions differently. But of course, how we understand our past actions is likely to affect our future actions.

The second mechanism works via the "self-fulfilling prophesy." Here, ideology changes how other people respond to the actor, which, in turn, changes what the actor does in the future (see Jussim, 1986, for a critical review). The paradigm example of that mechanism is the teacher who pays more attention and works harder with children identified as "smart," than children identified as "slow," thereby making the "smart" ones "smarter." Thus, being labeled as "smart" or "slow" does not itself make kids smarter or slower. The teacher's behavior must also change accordingly.

The final mechanism-the one that I believe has the most profound effects-is when institutional structures are changed in a way that is consistent with the ideology. The industrialist believes that workers are only motivated to work by wages and then constructs an assembly line that reduces work to such meaningless bits that there is no reason to work aside from the wages. 
The politician believes that self-interest motivates all behavior, that people are entitled to keep the spoils of their labors, and that people deserve what they get and get what they deserve. Said politician helps enact policies that erode or destroy the social safety net. Unsurprisingly, people start acting exclusively as self-interested individuals. "If it's up to me to put a roof over our heads, put food on the table, and make sure there's money to pay the doctor and the kids' college tuition bills, then I better make sure I take care of myself." Because I think it is much harder to change social structures (Mechanism 3 ) than it is to change how people think about themselves (Mechanism 1), which psychotherapy can effectively address, or how they think about others (Mechanism 2), which education can effectively address, and because social structures affect multitudes rather than individuals, we should be most vigilant about the effects of ideology on social structures.

\section{SPHERES OF SOCIAL LIFE}

For the dominance of self-interest to be ideology, then Mrs. Thatcher notwithstanding, there must be alternatives. What are they, and where do they operate? Alan Fiske (1991, 1992; Fiske \& Tetlock, 1997) offered a general framework for answering those questions when he proposed that all societies are governed by four fundamental forms of social relations: communal sharing, authority ranking, equality matching, and market pricing. One can find all four types of relations in virtually every society, but societies differ in which of those relations is dominant and in which areas of life are governed by which types of relations. Communal sharing ("what's mine is yours"), authority ranking ("you do what I tell you"), and equality matching ("thanks for mowing my lawn last week when I was away; I'll take care of yours today") are dominant in many societies, whereas market pricing ("what will you pay me to do it?") plays a negligible role. For example, Fiske (1991) describes the Moose (MOOsay) culture in what is now Burkina Faso as dominated by communal sharing (see Bohannan, 1955, and Douglas, 1963, for discussion of other examples). The unit of "ownership" is the dyad, or the family, or even the entire community, and people do not keep track of who gives what to whom or who owes what to whom. In much of Burkina Faso, friends and neighbors will happily come to help cultivate one's fields. The provision of beer or food is much appreciated, as is the offer to reciprocate (equality matching) when it is time for the neighbors to cultivate their own fields. An offer of payment, however, would be an insult. And an offer to pay for land would be incomprehensible. When the French colonized the Moose, Moose were shocked by the extent to which the colonizers relied on market pricing. According to Fiske, the Moose 
developed the myth that French parents kept ledger books and when their children became adults, the parents presented the children with a bill for the costs of rearing them.

In modern, Western societies, market pricing dominates. But market pricing arrangements also exist in societies dominated by communal sharing, even with respect to activities where Westerners would find it repugnant. It was commonplace among the Moose to consider exchanging a slave or a wife for a quantity of brass, and comprehensible and conceivable (though humiliating) to exchange one's children for food. At the same time, even in the West, where market pricing dominates, friends would regard it as bizarre if you tried to reimburse them for the dinner they cooked you.

Market pricing governs relations in the market, where it is understood that people are interested not in equity but in gain, and where the principal lubricant of exchange is not trust, or authority, or reciprocity, but contracts. Market pricing is enormously facilitated by (or perhaps even made possible by) a medium of exchange like money. Money allows people to engage in transactions anonymously and by long distance. As Fiske puts it, transactions need leave no traces, because they can be paid for there and then. There is no need to keep score and no need to expect explicit and direct reciprocation. The market system enables more indirect reciprocation. Buyers do not require the people who sell to them to turn around and buy from them, as long as there are some (potentially anonymous) buyers for every seller. Money also makes it possible to exchange things that would otherwise seem incomparable, or incommensurable. So long as each thing can have a price, then the value of seemingly incomparable things can be compared by means of their prices. This permits a kind of fluidity and freedom in social relations that the other types of social rules do not. For example, in an equality-matching framework, how does one decide what kind of reciprocation for a dinner invitation, aside from a return dinner invitation, is equitable? Since the value of such social acts is not just their price-indeed, it may be totally unrelated to their price-the only way to assure equity is to reciprocate in kind. With market pricing and a medium of exchange, that is no longer necessary. Value is price, everything has a price, and everything can be exchanged for everything else.

Fiske observes that when people deploy one form of social relation when a different one is appropriate, it is often regarded not just as a mistake-a social faux pas-but as a transgression. And there is directionality to that moralization. It is socially acceptable, though perhaps foolish, to rely on communal sharing in a market setting ("here's a basket of tomatoes; take what you need and pay what you can afford."). But it is taboo to err in the other direction (for example, by giving your mother a tip after a delicious Thanksgiving dinner). 
Put another way, Fiske's idea that different aspects of life are governed by different norms for appropriate social relations implies that there are barriers that cannot be crossed, goods that are incommensurable, tradeoffs that cannot be made. He refers to such tradeoffs as "taboo tradeoffs" (e.g., Fiske \& Tetlock, 1997). You simply can't put a price on your mother's Thanksgiving dinner. But the market pricing model assumes that all goods are commensurable. Even goods that are not officially market goods nonetheless have what economists call "shadow prices." Thus, as economist Gary Becker famously argued in his economic analysis of marriage, people stay in unsatisfactory marriages only when the "costs" of breaking up and finding a new partner exceed the "costs" of staying in the marriage (Becker, Landes, \& Michael, 1976). Thus, for example, one can reply to the assertion that "you can't put a price on life" by saying, "Yes, you can; we do it all the time." In fact, when the U.S. Office of Information and Regulatory Policy (OIRA) carries out its mandatory review of all significant federal agency policy initiatives, it verifies that the agency effectively considered cost-benefit analysis, which often requires tradeoffs between life and monetary costs (that is, "Is this safety regulation worth the cost?"). Jonathan Baron (1986) has argued that despite what people say about incommensurability, they make tradeoffs between incommensurables, such as life and property, all the time. By facing facts, Baron suggests, we could make such tradeoffs deliberately, rationally, and consistently. But a question arises as to whether, if we faced the facts and acknowledge such tradeoffs, it would become easier over time to put a price on life, so that our reverence for life would diminish and it would become just another good (e.g., Schwartz, 1988). In other words, a little bit of self-deception about the sanctity of life may keep its value higher than it would be otherwise. Indeed, some have argued that the mere act of making an explicit comparison of seemingly incommensurable goods cheapens the goods. As philosopher Joseph $\operatorname{Raz}(1986$, p. 22) put it: "It is impoverishing to compare the value of a marriage with an increase in salary. Likewise, it diminishes one's potentiality as a human being to put a value on one's friendship in terms of improved living conditions." Fiske and Tetlock (1997, p. 284) put the matter this way:

It is an objective fact that, as economists insist, individuals and societies make de facto trade-offs and must do so. However, very few of these are made reflectively, and fewer still are made public and explicit. Nor do people inherently make such choices according to the Market Pricing metric of costs/benefits. At most points in history in most societies, most people undertake most of their interactions without consciously choosing among all possible alternatives....[P]eople confront problematic trade-offs among 
compartmentalized models only when people cease to take for granted cultural practices that are normally common sense.

Arguably, it is the aim of market pricing as ideology to change what we take to be "common sense."

In most Western societies, market pricing is the dominant form of social relation-not just in the market but in public life more generally. The other forms of social relations are mostly relegated to friends and family. But the domains of applicability of those types of relations are dynamic. Over time, as practices evolve, what is taboo becomes acceptable and what is acceptable becomes normal. Though in earlier eras it would have been unthinkable for children to expect payment for doing household chores, that practice has become commonplace. And though it is a topic of current controversy whether students should win cash prizes for school attendance and exam performance, in a somewhat desperate attempt to improve school performance, such practices are now getting serious attention. It is not at all implausible that 20 years from now, such practices will have become routine.

One way of understanding the Israeli daycare center and the Swiss nuclear waste referendum examples is that the introduction of fines or the offer of compensation relocated the activities from a different social sphere into the market sphere. Both Israeli and Swiss societies are dominated by market pricing. In a society that is not dominated by market pricing, it seems doubtful (though I know of no evidence) that simply threatening a fine or offering a fee would have such an immediate effect. But in a world dominated by market pricing, it takes little effort to shift the character of an activity in that direction. Of course, there are some domains of life, even in the United States, that are currently protected from market pricing. However, barriers between domains are not cast in concrete, and thus it is possible that in the future, market pricing will encroach on even more domains of life. Consider this observation from Gary Becker (1976, p.8):

I have come to believe that the economic approach is a comprehensive one that is applicable to all human behavior, be it behavior involving money prices or imputed shadow prices, repeated or infrequent decisions, large or minor decisions, emotional or mechanical ends, rich or poor persons, men or women, adults or children, brilliant or stupid persons, patients or therapists, businessmen or politicians, teachers or students.

It is not hard to imagine how, guided by such a claim, people would come to understand all their social relations as market pricing relations (see Schwartz, 
1994). And the nature of those relations would change as a result. In a world like this, we would not have to worry that financial motives would crowd out moral ones, because the moral ones would already have disappeared.

A suggestion that such a change in people's understanding of their social relations and responsibilities to one another can occur on a society-wide scale comes from a recent content analysis of Norwegian newspapers by Hilde Nafstad, Rolv Blakar, Erik Carlquist, Joshua Phelps, and Kim Rand-Hendriksen (2009). The analysis, which covered a period from 1984 to 2005, found a shift from what the authors call "traditional welfare ideology," long the dominant sociopolitical characteristic of Norwegian society, to what they call "global capitalist ideology." That shift included increased use of market-like analysis to discuss all aspects of life, increased reference to the values of individualism and self-interest, and a redefinition of the social contract between individuals and society along market pricing lines. Of course, the fact that newspapers write about social relations in a particular way does not mean that people live them in that way, but it is at least plausible that newspaper coverage either captures a shift in how people think about and act toward one another, or facilitates such a shift, or both.

Dale Miller (1999) has presented evidence of the pervasiveness what he calls the "norm of self interest" in American society. College students assume, incorrectly, that women will have stronger views about abortion issues than men, and that students under the age of 21 will have stronger views about the legal drinking age than those over 21, because women and minors have a stake in those issues that men and older students do not. The possibility that one's views could be shaped by conceptions of justice or fairness, rather than self-interest, does not occur to most people. ${ }^{5}$ Miller points out that the self-interest norm has been institutionalized in the legal setting. The adversarial legal system is premised on the self-interest norm. Opposing parties are responsible for vigorously defending their own self-interests, rather than allowing the judiciary to independently and neutrally pursue the truth. ${ }^{6}$ In addition, courts require parties who write "friend of the court" briefs to have "standing" - that is, an interest in the outcome of the case. Having "skin in the game" is the only way to assure that your opinion will not be frivolous.

\section{DRAWING BOUNDARIES BETWEEN SPHERES OF SOCIAL LIFE}

Given that market pricing is just one of several ways of regulating how people relate to one another, and given that the sorting of life domains into categories of social relation is itself a dynamic process, a question naturally arises as to 
how we should decide what goes where. Can normative standards be used to determine whether one mode of social relation is better than another? One could accept, for example, my argument that the dominance of market pricing that we observe in modern, Western society is the product of historical contingency - that it has been otherwise in the past, could be otherwise in the future, and is otherwise in other cultures. But one could then argue, as some do, that the dominance of market pricing represents social progress. It caters more than any other system to human freedom and autonomy. It enables people to pursue and get exactly what they want out of life with minimal transaction costs. Exchanges among strangers, which market pricing enables, would not be possible in systems governed by communal sharing (who is in your community?), authority ranking (from whom do you take orders?), or equality matching ("I don't have time to mow your lawn. Can I give you a gift certificate to The Home Depot instead?"). Thus, on grounds of freedom, autonomy, and efficiency, one could applaud the dominance of market pricing.

Alternatively, one could argue that whereas freedom, autonomy, and efficiency are goods, they are not the only goods. Michael Walzer (1983) makes such an argument in his book, Spheres of Justice. Rather than identifying a single abstract and overarching principle to govern the distribution of society's goods that should operate in all spheres of life, Walzer suggests that societies need multiple principles. For example, Walzer argues that in politics, the operative principle should be equality. With regard to basic goods and services, the operative principle should be meeting needs. With regard to honors and awards, the operative principle should be deservedness. As with Fiske's scheme, Walzer acknowledges that boundaries can shift and that principles can be contested. Nonetheless, he argues that thinking about allocating various types of goods requires nuance and subtlety. The dominance of market pricing threatens nuance and subtlety.

A second approach to assessing the normative status of market pricing is perhaps to accept that freedom, autonomy, and efficiency are important goods, and that they are best achieved by a system of market pricing, but that the effectiveness of market pricing itself depends on commitments to certain moral values. Without the widespread adoption of those moral values, markets will stop working as they should. And when markets stop working properly, they stop serving freedom, autonomy, and efficiency. For example, the productivity that comes from competition can be undermined by the ruthless abuse of market power (involving price fixing and special dealing) by a few market participants. Efficiency can be undermined by massive transaction costs that arise if participants cannot rely on basic honesty. Importantly, values like basic decency and honesty arise out of other systems of social relations. 
Market pricing does not encourage them, and may even erode them. Even Adam Smith, the father of free market economics, held that view. The Wealth of Nations (1776/1937), his paean to the marvels of the market, followed another book, The Theory of Moral Sentiments (1753/1976), in which he suggested that a certain natural sympathy for one's fellow human beings provided needed restraints on what people would do if they were left free to "barter, truck, and exchange one thing for another." Smith's view, largely forgotten by modernity, was that efficient market transactions were parasitic on aspects of character developed in nonmarket social relations. As I have argued elsewhere (Schwartz, 1986, 1994), Smith was right about the importance of "moral sentiments," but wrong about how "natural" they are. In a market-dominated society, the "moral sentiments" may disappear so that nothing can rein in self-interest. The same can happen if market activities are walled off from the social relations that exist in other spheres of life, where moral attributes like sympathy might actually be nurtured.

Echoing that last point, Karl Polanyi (1944) suggested that the "great transformation" of society ushered in by industrial capitalism was not so much assembly lines and mass production as it was the separation of the economic sphere of life from other spheres. "Economics," Polanyi pointed out, began as "home economics," which meant that economic activity was integrated into the rest of life. With the growth of the factory system, economic activity became increasingly autonomous-separate from the rest of life. And now, as market pricing becomes ever more dominant in regulating social relations, that autonomy hardly matters, since the "rules of the game" outside the market are often the same as the rules of the game inside the market.

The dominance of market pricing represents what one might call "economic imperialism." Can markets continue to provide the benefits they are meant to when they dominate other forms of social relations? President Obama apparently thinks not. In a press conference on December 18, 2008, Obama said that the bankers and financiers must "ask, not just is it profitable, but is it right." In a society dominated by market pricing, where do the bankers go to ask "Is it right?" and find an answer? Each time the scope of the market extends itself, it becomes increasingly difficult for people to envision an alternative to its logic. As a result, the self-interest assumptions built into market pricing become "laws of nature" by default.7

A nice demonstration of how market transactions benefit from sensibilities that are developed in nonmarket spheres of life, and how those sensibilities can be eroded, comes from research on judgments of fairness in market situations. In a study by Daniel Kahneman, Jack Knetsch, and Richard Thaler (1986), people were asked to judge the fairness of a range of different hypothetical 
economic transactions. Each situation was described, and people were asked to assess whether the behavior in question in each situation was fair or unfair. Here was one situation:

A hardware store has been selling snow shovels for $\$ 15$. The morning after a large snowstorm, the store raises the price to $\$ 20$. Is this fair?

Consider how a person might go about answering a question like this. From what perspective should one assess fairness? Suppose one was operating purely from a market pricing perspective. Market economics teaches us that both buyers and sellers are out to get as much as they can for as little as they can get away with. If the store owner can get $\$ 20$ for a snow shovel, he is entitled to it. If the buyer can find the same shovel for less in another store, he should buy the shovel at the other store. Competition substitutes for fairness in the marketplace. Store owners who price-gouge will lose business to competitors who charge lower prices. Store owners who price-gouge at a moment of high demand may turn off previously loyal customers and lose future business. In any case, the store owner should be guided by the goal of maximizing profit. If he mistakenly charges $\$ 20$, he is not acting unfairly but, rather, he has misgauged the competition, the reaction of his customers, or both. Therefore, the market pricing answer to this question is that yes, of course, it is fair to charge $\$ 20$. More accurately, the market pricing answer might be that "fairness" has nothing to do with it. The real question is whether it is profitable to charge $\$ 20$, and that question will have different answers in different circumstances.

Now suppose one was operating from a nonmarket pricing, or not purely market pricing perspective. Suppose that notions of fairness implied responsibility to meet the community's needs and to honor the loyalty of regular customers. Suppose that one was entitled to a reasonable profit, but not to whatever the traffic would bear. From that perspective, one might decide that it was unfair to charge $\$ 20$ for the shovel, even if one could get away with it.

So how do people answer the question? Eighty-two percent of the study participants judged the $\$ 20$ price to be unfair, suggesting that the majority of people do not make decisions of that kind from within a purely market pricing perspective. Here is another pair of examples:

A small photocopying shop has one employee who has worked in the shop for six months and earns $\$ 9$ per hour. Business continues to be satisfactory, but a factory in the area has recently closed and unemployment has increased. Other small shops have now hired reliable workers at $\$ 7$ per hour to perform jobs similar to those done by the photocopy shop 
employee. The owner of the photocopying shop reduces the employee's wage to $\$ 7$ per hour. Is this fair?

A small photocopying shop has one employee who has worked in the shop for six months and earns $\$ 9$ per hour. Business continues to be satisfactory, but a factory in the area has recently closed and unemployment has increased. Other small shops have now hired reliable workers at $\$ 7$ per hour to perform jobs similar to those done by the photocopy shop employee. The current employee leaves, and the owner of the photocopying shop decides to pay a replacement $\$ 7$ per hour. Is this fair?

Do the two situations evoke the same evaluation? From a purely economic perspective, the situations are equivalent. Bosses pay the lowest wage they can get away with. A supply of surplus labor enables them to lower the wages of current employees, or else replace them with unemployed people who will accept the lower wage. Interestingly, $83 \%$ of the respondents in the study thought that the first situation was unfair. That is not because they believed that working in a photocopying shop was simply worth $\$ 9$ per hour, because $73 \%$ of the respondents thought the second situation was fair. More likely, many factors influence whether people believe a wage is fair, including the employer's profit margin and the going wage for similar work in the area.

Importantly for that example, another relevant factor is the wage history of the particular employees involved. The employee in the first example initially earned $\$ 9$ per hour, which became his "reference wage." Unless the employer suffered an economic hardship, the reference wage could not fairly be reduced. It certainly could not be reduced just because other people were willing to work for a lower wage. It is clear from people's belief that it is fair to pay a lower wage to a new employee for the same job that the reference wage attached to the employee and not the job.

It should not be concluded that the respondents in this study were antiboss or anticapitalist. Their sense of fairness seemed to include not just a reference wage and a reference price but also a reference profit. Respondents overwhelmingly agreed that it was fair to increase prices or decrease wages if profits were being threatened, especially if the threat to profits came from circumstances outside the employer's control. In fact, respondents treated profits above the reference profit as fair if they did not result from increased prices or decreased wages but instead resulted from a cheaper source of raw materials or a more efficient production process. In other words, producers and retailers were not required to pass their savings on to purchasers. 
Responses to those examples indicate that most people think it is perfectly appropriate to apply moral standards in evaluating economic transactions. The market is not an amoral playing field in which anything that is not illegal is acceptable. The market is not a place in which the naked and unrestrained pursuit of self-interest is condoned. People may have come to expect the worst in the market, but they have not yet come to accept it. Instead of allowing economic considerations to encroach on the moral domain, the respondents in this study seem to insist that moral considerations should encroach on the economic domain.

On its face, that demonstration of concern about fairness suggests that market pricing is not as dominant as I have been suggesting. It also suggests that, in contrast to the examples with which this chapter began, sometimes moral motives and self-interested ones can coexist. People can be concerned about maximizing self-interest and concerned about treating others fairly. That coexistence of motives is almost certainly what Adam Smith had in mind when he wrote about natural sympathy. If people are willing to impose standards of fairness in the marketplace, then perhaps there is no reason for concern about economic imperialism and its effects.

Perhaps, but I do not think so. Standards of fairness must come from somewhere. Since there is no place for fairness within the market domain (and the accompanying market pricing ideology) itself, those standards must be developed in other domains. They are likely developed, encouraged, and sustained in various nonmarket institutions, such as the family and the local community. They are then imported, at least by some people, into market situations. As long as the nonmarket institutions retain their noneconomic character and purpose, concern for fairness can continue to be nurtured. But as economic considerations invade them, the concern for fairness will weaken. The study participants' concern for fairness may show only that economic considerations did not yet deeply penetrate the nonmarket institutions that helped shape them. But that offers no guarantees for the future. People possess no built-in safeguards against the erosion of concern for fairness. There is nothing natural, automatic, or inevitable about this concern. It must be learned, and it must be taught.

In fact, other concepts can be taught quite easily in its place. Howard Kunreuther (1986) asked many of the fairness questions just reviewed to a group of MBA students at a prestigious business school. In general, their fairness judgments differed significantly from the judgments of the respondents in the original study. In general, the MBA students believed that all efforts to maximize profit were fair. All's fair-from increasing prices to decreasing wages-in the market. Did the students learn that in their MBA program, or did they seek MBAs because they already believed it? Said another way, did Kunreuther's results reflect a training effect or a selection effect? 
There is no way to know from the Kunreuther study, but a hint is provided by the research of Robert Frank, Thomas Gilovich, and Dennis Regan (1993). In a study of behavior in prisoner's dilemma games, they found that economics students were more likely to defect than noneconomics students. Moreover, the difference between economics and noneconomics students got larger as the students progressed through school. That difference held up even when the authors statistically controlled for gender differences (the study of economics is more male dominated than other disciplines, and males are known to be more likely to defect in prisoner's dilemma games than females). ${ }^{8}$

So here we have what may be an example of ideology in action. Economics students learn about the logic of self-interest maximization, come to expect it in others, and come, increasingly, to display it themselves. ${ }^{9}$ Their professors have not helped them to discover a fundamental truth about human nature so much as they have helped them create it. Results like those suggest that there is no reason to count on the concern for fairness as an ineluctable part of our approach to social life.

Economist and philosopher Amartya Sen (1976) has argued that the concern for fairness originates from a source that the logic of the market cannot encompass. He calls that source of concern "commitment." To act out of commitment is to do what one thinks is right and what will promote the public welfare, regardless of whether it promotes one's own interests. It is to act out of a sense of responsibility as a citizen. Acts of commitment include voting in large general elections and doing one's job to the best of one's ability-going beyond the terms of the contract, even if no one is watching and there is nothing to gain from it. They include refusing to price-gouge during times of shortage, refusing to capitalize on fortuitous circumstances at the expense of others, willingness to tolerate nuclear waste dumps in one's community, and coming to pick up one's toddlers from daycare on time.

Acts of commitment like that occur routinely. They hold society together. But they are a problem for the logic of self-interest. As Sen (p. 329) says: "Commitment...drives a wedge between personal choice and personal welfare, and much of traditional economic theory relies on the identity of the two." $\mathrm{He}$ continues:

The economic theory of utility ... is sometimes criticized for having too much structure; human beings are alleged to be "simpler" in reality... precisely the opposite seems to be the case: traditional theory has too little structure. A person is given one preference ordering, and as and when the need arises, this is supposed to reflect his interests, represent his welfare, summarize his idea of what should be done, and describe his actual 
choices and behavior. Can one preference ordering do all these things? A person thus described may be "rational" in the limited sense of revealing no inconsistencies in his choice behavior, but if he has no use for this distinction between quite different concepts, he must be a bit of a fool. The purely economic man is indeed close to being a social moron.

Said more prosaically, the economists' conception of rational self-interest, served so well by market pricing as the dominant mode of social relations, is too reductive. Like Skinner's conception of human beings as reward seekers, it exalts one aspect of a human nature that is complex and multifaceted and ignores all the rest. The economists' flawed conception of human behavior has infiltrated the legal arena through the "law and economics" movement, in which laws and judicial opinions are evaluated according to their economic efficiency. To calculate economic efficiency, actors are presumed to be rational and self-interested. Because of the self-fulfilling character of ideology, we should not be sanguine that this reductive distortion of human nature will reveal itself. Unless there is a collective effort to combat ideology-a collective effort to sustain the other kinds of social relations Fiske articulates-we will all become the rational self-interest maximizers that economists have always assumed we were.

\section{CHOOSING THE RIGHT FRAME}

If we accept Fiske's conceptual framework as a reasonable empirical description of the different modes of social relations, and we further accept that locating different activities in one or another mode is a dynamic process that is subject to historical change, is there anything we can say about how modes should be delineated and how activities should be assigned? What "metanorms" can we use for assessing the social norms we have?

I do not have an answer to that question, but I believe there is a plausible candidate in common use that is unsatisfactory. We cannot use cost-benefit analysis to decide which activities to locate in which domains of social activity. Cost-benefit analysis is problematic because to use it, costs and benefits must be denominated on a common scale. The obvious scale to use is money, though it does not really matter whether we use money or utility. Once the move is made to locate an activity on a common scale, the activity in question is placed in the market pricing system of social relations. Thus, cost-benefit analysis is not a neutral instrument for evaluating the efficacy of different modes of social relations. It prejudges the scale of evaluation, which in turn may prejudge the evaluation. 
We can see that effect by looking at what is often regarded as the gold standard for assessing cost and benefits of public policies-a technique known as "contingent valuation." With contingent valuation, instead of guessing the value of costs and benefits, one asks: "How much would you be willing to pay to have your lake cleaned up of pollutants?" or "How much would I have to pay you for permission to dump pollutants in your lake?" Analysts aggregate such "willingness to pay" and "willingness to accept" judgments across affected parties to gauge the welfare consequences of policies. Leaving aside some serious internal problems with contingent valuation, ${ }^{10}$ consider the Swiss deciding about nuclear waste dump siting. When asked with no mention of money, $51 \%$ said they would accept the dump in their community. But when asked with the promise of money-a straightforward "willingness to accept" type of question-only $25 \%$ said yes. So rather than being a neutral tool for measuring costs and benefits, contingent valuation actually changed people's judgments of costs and benefits. By turning an issue into a market pricing matter, people thought differently about it and made different decisions. This analysis tells us that however useful contingent valuation, and cost-benefit analysis more generally, may be as off-the-shelf tools for assessing the welfare consequences of public policies, they cannot be used effectively to assess the welfare consequences of locating activities in certain modes of social relations. Since the very act of using cost-benefit analysis locates the activities in a market pricing framework, it shapes our evaluation. The reliance on contingent valuation represents another example of ideology in action. Policymakers take it to be a neutral tool for assessing the welfare consequences of various policies, and accept its results at face value. But instead of merely measuring people's preferences, it can mold them.

\section{MONEY CHANGES EVERYTHING}

This is not an idle, or merely theoretical, concern. Kathleen Vohs, Nicole Mead, and Miranda Goode (2006) showed in a series of ingenious studies that even subtle cues about money, like playing Monopoly or viewing a computer screensaver with various denominations of paper money floating underwater, induced people to be less helpful to others and to prefer working alone to working in groups. In addition, Sanford DeVoe and Sheena Iyengar (2009) have shown that when experiment participants are compensated with money, they favor distribution based on contribution, whereas when they are compensated with goods that have clear monetary value but are not mediums of exchange, they exhibit concern for fairness and favor equality of distribution. In other words, candy should be divided equally among participants whereas 
money should be divided according to effort or work accomplished. Both of those studies suggest that given the dominance of market pricing as the model for social relations, it does not take much to tip people's considerations in that direction.

\section{CONCLUSION}

In his book, A Conflict of Visions: Ideological Origins of Political Struggles, Thomas Sowell (1987) distinguishes between what he calls "constrained" and "unconstrained" visions of human nature. The constrained vision, exemplified by Thomas Hobbes, focuses on the selfish, aggressive, dark side of human nature, and it assumes that we cannot change human nature but must instead impose constraints through an all-powerful state, the Leviathan. The unconstrained vision, perhaps best exemplified by Jean-Jacques Rousseau, sees enormous human possibility, and it condemns the state for subverting all that is good in human nature. This chapter has argued that both Hobbes and Rousseau are wrong. "Nature" dramatically underspecifies human nature. Within broad limits, we are what society asks and expects us to be. If society asks little, it gets little. Under those circumstances, we must be sure that we have arranged social rules and incentives in a way that induces people to act in ways that serve the common good. If we ask more of people, and arrange our social institutions appropriately, we will get more. As Clifford Geertz (1973) has said, human beings are "unfinished animals," and what we can reasonably expect of people depends on how our social institutions "finish" them. [Editor's Note: Ross and Shestowski (chapter 17, this volume) develop similar themes.]

"Rational economic man" as a reflection of human nature is a fiction-an ideology. But it is a powerful fiction, and it becomes less and less fictional as it increasingly pervades our institutions and crowds out other types of social relations. Because of its self-fulfilling character, we cannot expect this fiction to die of natural causes. To extinguish it, we must hold onto the alternatives. And that will not be easy.

\section{NOTES}

1. For readers who think that the offer of compensation served as a signal that nuclear waste dumps are dangerous, Frey and Oberholzer-Gee (1997) found no evidence that those offered money regarded the dump as more dangerous than those not offered money.

2. One group of students learned that they would receive $\$ 0.10$ for performing the task, while another group learned that they would receive $\$ 4.00$. Both 
groups put in less effort on average than the uncompensated group. However, this result was only statistically significant for the $\$ 0.10$ group.

3. See chapter 1 , this volume, for a discussion of various other definitions of "ideology."

4. Though Skinner acknowledged the potential power of "fines" —of punishment-he thought rewards were much more effective instruments of behavior control and so focused most of his attention on them.

5. Though interestingly, respondents typically impute self-interest motives to others and hold themselves out as exceptions to the "norm of self-interest."

6. See Callan and Kay (chapter 6, this volume) for a discussion of the premise of self-interest in the adversarial legal system.

7. It is worth noting that merely to ask the normative question about the benefits and costs of market pricing is to violate the assumptions of thinkers like Gary Becker and B. F. Skinner. For Becker, the economic framework of rational choice simply describes human nature as it is and has always been. For Skinner, the explicit use of rewards and punishments simply capitalizes on human nature as it is. From my point of view, and that of Fiske, the views of Becker and Skinner are examples of ideology-pieces of idea technology that are false as generalizations, but can become true as society remakes itself to conform to the image of human nature these theorists articulate.

8. Frank, Gilovich, and Regan (1993) also found that economists, in contrast to noneconomists, are more likely to free-ride in an investment game, make smaller offers in an ultimatum bargaining game, and are less likely to give to charity.

9. Frank, Gilovich, and Regan (1993) also found evidence that students of economics were more cynical than other students in judging the honesty of other people in a variety of hypothetical situations, like returning a lost wallet with cash in it.

10. Typically, answers to "willingness to pay" questions are less than half of answers to "willingness to accept" questions for the same good, although they ought to be two ways of asking the same question.

\section{REFERENCES}

Baron, J. (1986). Tradeoffs among reasons for action. Journal for the Theory of Social Behavior, 16, 173-95.

Becker, G. (1976). The economic approach to human behavior. Chicago: University of Chicago Press.

Becker, G., Landes, E., \& Michael, R. (1976). An economic analysis of marital stability. Journal of Political Economy, 85, 1143-75.

Bohannan, P. (1955). Some principles of exchange and investment among the Tiv. American Anthropologist, 57, 60-70. 
Callan, M. J., \& Kay, A. C. (this volume). Associations between law, competitiveness, and the pursuit of self-interest, In J. Hanson (Ed.), Ideology, psychology, $\mathbb{E}$ law. New York: Oxford University Press.

DeVoe, S. E., \& Iyengar, S. S. (2009). Medium of exchange matters: The type of good distributed determines what's fair. Manuscript submitted for publication (copy on file with authors).

Douglas, M. (1963). The Lele of the Kasai. London: Oxford University Press.

Fiske, A. P. (1991). Structures of social life: The four elementary forms of human relations. New York: Free Press.

Fiske, A. P. (1992). The four elementary forms of sociality: Framework for a unified theory of social relations. Psychological Review, 99, 689-723.

Fiske, A. P., \& Tetlock, P. E. (1997). Taboo trade-offs: Reactions to transactions that transgress the spheres of justice. Political Psychology, 18, 255-97.

Frank, R. H., Gilovich, T., \& Regan, D. T. (1993). Does studying economics inhibit cooperation? Journal of Economic Perspectives, 7, 159-71.

Frey, B. S., \& Oberholzer-Gee, F. (1997). The cost of price incentives: An empirical analysis of motivation crowding-out. American Economic Review, 87, 746-55.

Geertz, C. (1973). The interpretation of cultures. New York: Basic Books.

Gneezy, U., \& Rustichini, A. (2000a). A fine is a price. Journal of Legal Studies, 29, 1-17.

Gneezy, U., \& Rustichini, A. (2000b). Pay enough or don't pay at all. Quarterly Journal of Economics, 115, 791-810.

Heyman, J., \& Ariely, D. (2004). Effort for payment: A tale of two markets. Psychological Science, 15, 787-93.

Jussim, L. (1986). Self-fulfilling prophecies: A theoretical and integrative review. Psychological Review, 93, 429-45.

Kahneman, D., Knetsch, J. L., \& Thaler, R. H. (1986). Fairness as a constraint on profit seeking: Entitlements in the market. American Economic Review, 76, 728-41.

Kunreuther, H. (1986). Comments on Plott and on Kahneman, Knetsch, and Thaler. Journal of Business, 59, S329-335.

Lepper, M. R., Greene, D., \& Nisbett, R. E. (1973). Undermining children's intrinsic interest with extrinsic rewards: A test of the "overjustification" hypothesis. Journal of Personality and Social Psychology, 28, 129-37.

Lepper, M. R., \& Greene, D. (Eds.) (1978). The hidden costs of reward: New perspectives on the psychology of human motivation. Hillsdale, NJ: Lawrence Erlbaum.

Miller, D. T. (1999). The norm of self-interest. American Psychologist, 54, 1053-60.

Nafstad, H. I., Blakar, R. M., Carlquist, E., Phelps, J. M., \& Rand-Hendriksen, K. (2009). Globalization, neo-liberalism, and community psychology. American Journal of Community Psychology, Online First, January 7, 2009.

Polanyi, K. (1944). The great transformation: Economic and political origins of our time. New York: Rinehart.

Raz, J. (1986). The morality of freedom. New York: Oxford University Press. 
Ross, L. \& Shestowsky, D. (this volume). Two Social Psychologists' Reflections on Situationism and the Criminal Justice System, In J. Hanson (Ed.), Ideology, psychology, \& law. New York: Oxford University Press.

Sahlins, M. (1976). The use and abuse of biology: An anthropological critique of sociobiology. Ann Arbor: University of Michigan Press.

Schwartz, B. (1982). Reinforcement-induced behavioral stereotypy: How not to teach people to discover rules. Journal of Experimental Psychology: General, 111, 23-59.

Schwartz, B. (1986). The battle for human nature: Science, morality and modern life. New York: W. W. Norton.

Schwartz, B. (1988). Some disutilities of utility. Journal of Thought, 23, 132-47.

Schwartz, B. (1990). The creation and destruction of value. American Psychologist, $45,7-15$.

Schwartz, B. (1994). The costs of living: How market freedom erodes the best things in life. New York: W. W. Norton.

Schwartz, B. (1997). Psychology, "idea technology," and ideology. Psychological Science, 8, 21-27.

Schwartz, B., Schuldenfrei, R., \& Lacey, H. (1978). Operant psychology as factory psychology. Behaviorism, 6, 229-54.

Sen, A. (1976). Rational fools: A critique of the behavioral foundations of economic theory. Philosophy and Public Affairs, 6, 317-44.

Sowell, T. (1987). A conflict of visions: Ideological origins of political struggles. New York: William Morrow.

Smith, A. (1753/1976). The theory of moral sentiments. Oxford, UK: Clarendon Press. Smith, A. (1776/1937). The wealth of nations. New York: Modern Library.

Taylor, F. W. (1911/1967). The principles of scientific management. New York: W.W. Norton.

Vohs, K. D., Mead, N. L., \& Goode, M. R. (2006). The psychological consequences of money. Science, 314, 1154-56.

Walzer, M. (1983). Spheres of justice: A defense of pluralism and equality. New York: Basic Books. 